\title{
So Much More Than a Job: A Psychoanalytic Exploration of Healthcare Work
}

\author{
Nathan Gerard ${ }^{1 *}$ \\ ${ }^{1}$ Department of Health Care Administration, California State University, Long Beach, USA
}

*Corresponding Author: nathan.gerard@csulb.edu

Citation: Gerard, N. (2017). So Much More Than a Job: A Psychoanalytic Exploration of Healthcare Work. European Journal of Environment and Public Health, 1(2), 09. https://doi.org/10.20897/ejeph/81156

Published: December 30, 2017

\begin{abstract}
This paper explores the utility of psychoanalysis for understanding the underlying meaning of healthcare work. At times deeply fulfilling, while at other times demanding and thankless, the provision of healthcare takes a unique toll on the psyche. Psychoanalysis is particularly suited for highlighting the paradoxical character of healthcare work because of its focus on the unconscious, emotional and irrational aspects of psychic life. Exploring the latent meaning of healthcare work, as well as the complex interplay between work and worker, allows for deeper insight into contemporary issues of healthcare management and organization.
\end{abstract}

Keywords: healthcare employee behavior, healthcare management, psychoanalysis

\section{INTRODUCTION}

For many in healthcare, work is so much more than a job. By helping and healing others, healthcare workers provide a vital service to society that in turn offers a sense of deep fulfillment (Abbott and Wallace, 1990). Research continues to show that many (if not most) healthcare workers perceive their job as a "calling" (Wrzeniewski et al., 2003; Curlin et al., 2007).

And yet, if healthcare work is a calling, it is also a calling increasingly not worth heeding. Physician burnout is at an all-time high (Sadick, 2014), as is the troubling phenomenon of "compassion fatigue" (Yoder, 2010). Don Seymour illustrates the unique burden placed on healthcare workers with the following injunction: "Take care of more people who have growing expectations and more complex medical needs while providing increasingly sophisticated care with relatively fewer resources" (Futurescan, 2008). Ironically, by helping and healing others, healthcare workers may be making themselves sick.

This paper seeks to unpack the complex psychological nature of healthcare work through an appeal to psychoanalysis. Psychoanalysis is particularly suited for highlighting the paradoxical character of healthcare work because of its focus on the unconscious, emotional and irrational aspects of psychic life. This paper begins with a brief overview of the psychoanalytic approach to studying organizations, followed by an application of this approach to understanding the unique environment of healthcare. Throughout, conventional healthcare management concepts and initiatives are reframed in light of the underlying psychodynamics at play. This paper concludes with recommendations for improving the healthcare worker's experience from a managerial perspective.

\section{UNDERSTANDING ORGANIZATIONS PSYCHOANALYTICALLY}

The psychoanalytic approach to studying organizations has a long and varied history, beginning with Freud's own social theorizing (Freud, 1913; 1921; 1927; 1930) and continuing with the seminal contributions of members of the Tavistock Institute of Human Relations (Jacques, 1953; Trist and Sofer, 1959; Menzies Lyth, 1960; Bion, 
1961). Now in its third generation of scholars and practitioners, the Tavistock Institute continues to advance scholarship in organization theory and behavior (e.g., Aram and Baxter, 2009), as do the closely related organizations of The A. K. Rice Institute (ARKI), and the International Society for the Psychoanalytic Study of Organizations (ISPSO) (e.g., Sievers, 2009).

The distinguishing feature of this approach is its focus on irrational organizational behavior. Irrational behavior is defined by a turn away from reality, and specifically a turn towards a more primitive way of relating with the world (Kets de Vries, 1984). Moreover, because irrational behavior is often inconsistent with accepted norms or self-images, it is largely unnoticed or unavailable to conscious awareness. From this understanding follows the wellknown psychoanalytic prescription of making the unconscious conscious, or as Larry Hirschhorn (1989) colloquially puts it, "putting the manager back into his story... making him less the object of his unacknowledged fantasies and more the subject of his actions and conscious intentions" (p. 158). Key here is that the worker be put back into a more rational story, less beholden to unconscious wishes and more in contact with reality.

In what follows I illustrate how the psychoanalytic approach to studying organizations can be applied to the unique environment of healthcare.

\section{THE HEALTHCARE ORGANIZATION AS “SOCIAL DEFENSE SYSTEM”}

Psychoanalysis encourages us to consider the structure of an organization as a "social defense system." What does this mean? According to Hirschhorn and Young (1991), a social defense system is "a system of relationships that help people control and contain feelings of anxiety when facing their difficult work" (p. 223). We may think of the social defense system as the institutionalized equivalent of the neurotic symptom defined by Freud (1910): "We know that neurotic symptoms are structures which are substitutes for certain achievements of repression... [substitutes] we have to carry out in the course of our development from a child to a civilized human being" (p. 131). In other words, social defense systems, like neurotic symptoms, are structures evoked to survive our transition into adulthood—or in the case of working life, our transition into the modern organization-but not without a corresponding cost (van Eeden and Cilliers, 2009). The formal structures of a hospital serve as a poignant example to bring this cost to light.

On the surface, a hospital's clearly delineated structures—its formal divisions and departments, roles and tasks-are undoubtedly vital for workers to carryout their work efficiently and effectively. From a psychoanalytic perspective, however, they take on deeper symbolic significance, potentially serving as "achievements of repression" (Freud, 1910) that create barriers to improvement. This was precisely what psychoanalyst Menzies Lyth $(1960,1991)$ discovered in her seminal study of nurses in a London teaching hospital. Specifically, Menzies Lyth (1991) observed how nurse-patient relationships became "fragmented by the work organization, in which all the nurses looked after all the patients indiscriminately" (p. 363). As a result, "close, intimate, and lengthy contact between them was limited" which over time led to a sense of "depersonalization" among both nurses and patients (Menzies Lyth, 1991, p. 363).

From a psychoanalytic perspective, becoming indifferent or detached (i.e., depersonalized) are ways of defending against anxiety (Freud, 1918). In Menzies Lyth's case study, nurses had wished to defend against the anxieties arising from patient intimacy and its corresponding risks of emotional attachment. Thus, on one hand, depersonalization made the work tolerable - without it, the nurses may have resorted to more extreme behavior and even breakdown ${ }^{1}$ - but it also contributed to personal and organizational dysfunction, restricting "the full development of the [nurse's] understanding, knowledge, and skills that enable reality to be handled effectively and pathological anxiety to be mastered" (Menzies Lyth, 1991, p. 427). The consequence, as Menzies Lyth (1960) noted, was that "true mastery of anxiety by deep working-through and modification was seriously inhibited" (p. 110).

\section{Reassessing "Continuity of Care"}

Menzies Lyth's illustration of a hospital's social defense system brings some much-needed depth to contemporary management initiatives in healthcare. Foremost among these are initiatives championed under the rubric of "continuity of care." Defined as "an implicit pledge that clinicians will communicate and coordinate across boundaries" (Haggerty et al., 2013, p. 269), continuity of care is a structural intervention seemingly geared towards tackling the very fragmentation Menzies Lyth (1960) documented over a half-century ago. And yet, repeated failure of continuity of care initiatives (Bickman, 1996; Chang et al., 1998) suggests the longstanding discontinuity of care serves some important purpose. Specifically, it may protect clinicians from the more anxietyprovoking situation of getting to know their patients personally and thereby feeling responsible for their welfare. Moreover, placing blame for failed initiatives on faulty payment structures (Bickman, 1996; Chang et al., 1998) or

\footnotetext{
${ }^{1}$ Menzies Lyth (1960): "the potential anxieties in the nursing situation were felt to be too deep and dangerous for full confrontation. They threatened personal disruption and social chaos” (p. 109).
} 
information-sharing systems (Kripalani et al., 2007), however warranted, may conveniently detract attention away from the unconscious resistances at play; resistances hitherto unexamined in the current literature.

From a psychoanalytic perspective, true continuity of care carries great risk, for it requires a level of intimacy with patients that challenges the image of the clinician who is supposed to know (Lacan, 1973). Healthcare managers who fail to take this underlying (and largely unconscious) reality into account risk implementing changes that not only fail, but cause more harm than good.

\section{THE DEPTHS OF A HEALTHCARE ORGANIZATION'S CULTURE}

To balance the focus on organizational structure, psychoanalytic scholars of organization also look to culture, and specifically to the "psychodynamically saturated field... between the organization's [espoused] culture and the individual's unconscious thoughts" (Tichy, 1989, p. 156). From a psychoanalytic perspective, people are often drawn into particular types of work not only because of their interest and training, but also because of the match between their own unconscious defenses and those reinforced by the organization's culture (Baum, 1989).

Some of the earliest thinking in this area comes from Freud (1913) himself, and in particular his interpretation of altruistic behavior displayed by his neurotic patients: "The tender altruistic trait of the neurosis therefore merely compensates for the opposite attitude of brutal egoism which is at the basis of it...Each of these over-good persons had a period of badness in his childhood" (p. 831, 898; italics in original). For Freud, because this "period of badness" was once dangerous (insofar as it threatened the child's primary relationships) it continued to be denied and repressed in adulthood, even taking on the opposite displays of tenderness and being "over-good."

Though Freud does not explore the link between early childhood and the types of work environments sought out later in life, the interpretation he provides proves useful to healthcare, a setting in which extraordinary kindness and selflessness are often seen as desirable attributes. Psychoanalyst David Levine (2010) helps bring this link to life through an example of an organization tasked with providing services to people with disabilities. The culture of this organization was one "in which doing good [was] an essential motivating factor" (p. 74). While there was nothing inherently wrong with this culture, it proved problematic when "doing good" became doing "the work of making something good that is not" (p. 75). Levine (2010) explains:

\footnotetext{
"When we find something bad in the world and work to make it good our work has a reparative function. It matters, however, whether the reparative function is done in response to a powerful conviction that we have made the world bad through our own action so that reparation is driven by guilt for harm done" (p. 75).
}

When doing good is driven by the need to repair for doing bad (i.e., by guilt for harm done), work becomes a setting in which employees are beholden to an unconscious fantasy. What became evident in Levine's case study was how both the organization and its workers were operating under the shared fantasy that good work could only be done through self-denial. Over time, this fantasy took a significant toll on employees:

"Since the employees were not clients, they had not suffered, and did not deserve attention. Indeed, to deny them attention served to secure a closer fit with the imagined experience of the client population. In other words, the organization created an emotional experience in its employees to which it did not attend. In doing this, the organization created for itself the opportunity to withhold empathy from its employees, which could be understood as an important part of its purpose" (Levine, 2010, p. 85-86).

Ironically, the organization created a feeling of impoverishment in its workers that mirrored the very impoverishment suffered by its clients. By rendering workers not worthy of having needs, the organization reinforced the very guilt (and the need to atone for this guilt) drawing workers to the organization. A vicious circle was thus enacted, keeping both individual and organization locked in a reinforcing system.

\section{Reassessing "Compassion Fatigue"}

While it would be a severe overgeneralization to assume that all healthcare workers unconsciously seek to repair a prior damaged self (or atone for their guilt) in their work, the interpretation Levine provides proves useful, not least in reframing the common understanding of "compassion fatigue." Known to effect anywhere from 16\% to 85\% of the healthcare workforce (Slatten et al., 2011; Potter et al., 2013; Smart et al., 2014), compassion fatigue is defined as "an extreme state of tension and preoccupation with the suffering of those being helped to the degree that it can create a secondary traumatic stress for the helper" (Figley 2005; 1995). Seen from a psychoanalytic vantage, however, compassion fatigue may be precipitated by an organization's culture, especially if that culture encourages the suppression of employees' needs. Moreover, drawing from Freud's (1913) analysis of altruism above, the "preoccupation with the suffering of those being helped" may actually stem not from compassion, but 
from its opposite: an unconscious feeling of contempt towards those being helped for not having to suppress their needs.

This alternative explanation of compassion fatigue doesn't intend to deny the reality of trauma caused by helping others, but rather illuminates trauma of a different sort; namely, the trauma arising from feeling unable to discover a relation to an organization's culture that involves being a whole person instead of merely a "helper." A whole person, in contrast to a "helper," can ask for help rather than simply give it. Put simply, a whole person can have needs worthy of attention.

\section{THE UNDERLYING MEANING OF HEALTHCARE WORK}

Having unpacked some of the structural and cultural dynamics at play in healthcare, we can now further distill the unique meaning of healthcare work. As noted in the introduction, one of the driving forces compelling people into healthcare careers is the opportunity to make a difference in the lives of others (Abbott and Wallace, 1990). Unconsciously, however, this opportunity comes with great burden, namely the burden of responsibility for another's welfare that is only partly within one's control (Menzies Lyth, 1960). Moreover, the desire to make a difference may actually stem from an unconscious desire to right the wrong of an early hostility (Freud, 1913; Levine, 2010).

What I wish to explore here is a deeper substratum of the healthcare worker's experience, a substratum in which the very notion of "health" garners its symbolic meaning and likely underpins the dynamics outlined above. This substratum is the conflict-ridden core of human psychology itself, as defined by psychoanalysis: namely, the intense and on-going exchange between the life-giving, pleasure-seeking force of love and the aggressive, destructive force of hate (Freud, 1920).

Reading the works of Melanie Klein $(1937,1946)$ in particular, we discover an infant overwhelmed by these dueling forces in the psyche. Unable to hold the opposing feelings of love and hate toward the same object (mother), the infant must accordingly split the object into "good" and "bad" parts, directing its love toward the former and hate toward the latter. What I wish to suggest is that this primary tension between love and hate symbolically infuses the notion of health, so much so that health becomes synonymous with love. While the extent of this infusion will undoubtedly vary by individual, the general tendency to imbue healthcare work with this meaning arguably remains pronounced and renders the provision of healthcare fraught. Specifically, the desire to make a difference becomes the desire to be different-free from hate and its corresponding sickness. In this sense, the pursuit of health becomes an impossible attempt at a self-cure for a fundamental split in the psyche.

So long as the underlying meaning of healthcare work carries this fantasy, the healthcare worker remains caught in an irrational struggle. Moreover, the provision of healthcare remains compromised, since to effectively help and heal others requires a realistic assessment of one's agency, along with a realistic understanding of the possibilities and limits of health.

\section{PRACTICAL IMPLICATIONS}

Given the depth that psychoanalysis brings to understanding healthcare, how might it also help healthcare managers? Menzies Lyth recognized early on that changing people without changing the organization's structure was deemed to fail. "A nurse cannot be more sensitive and intimately related to her patients when a nursing system based on multiple indiscriminate caretaking prevents her from ever really getting to know them well" (Menzies Lyth, 1991, p. 371). Menzies Lyth recommends that structures be modified to allow for nurses to relate to patients in a more intimate manner, while at the same time still feel "contained" by clear professional boundaries so as not to be overwhelmed by anxiety. While Menzies Lyth cautions against any simple managerial formula (intuiting, rightly, that the precise balance between intimacy and boundaries will depend on both the person and the situation), her overarching prescription remains clear-namely, erect structures that avoid fortifying pathological defenses, and instead mobilize human energies toward achieving realistic aims.

The same attunement Menzies Lyth brings to organizational structure can be brought to organizational culture. From a psychoanalytic perspective, the espoused mission and values of a healthcare organization cannot be taken at face value, but instead must be explored for their potential as "cover stories" for unconscious dynamics (Hirschhorn, 1989). Compassion fatigue, as we noted above, gives expression to a broader organizational dynamic in which the imposition of values ("doing good") reinforces unhealthy patterns of employee behavior rooted in early life. The aim of any management, therefore, following Hirschhorn (1989), should be to allow workers to "write their own story" when it comes to culture; a story with themselves, as whole persons, more fully in it.

Before embarking on any change initiatives, however, managers would do well to first familiarize themselves with "the identity of an organization," as Michael Diamond (1988) advocates: 
"Knowing the identity of an organization evokes the personal meaning, experience, and perception of organizational life in the mind of individual members, which helps us understand unconscious motivations that govern behavior and that distinguishes one organization from another" (Diamond, 1988, p. 168).

By coming to know this "organizational life in the mind," healthcare managers can better access what the experience of the organization is like for its workers, thereby creating initiatives better attuned to this psychic reality. Coinciding with this we might add "knowing the identity of the work," and in particular how the worker holds various types of work in the mind. As noted above, this entails getting to know the symbolic significance of core notions like "sickness" and "health."

Ultimately, healthcare managers should aspire to provide an outlet in which workers can find gratification not from fantasy, but from a realistic accomplishment of work. Only then, to quote Freud (1930), will the worker obtain "a secure place in a portion of reality, in the human community." Otherwise, we simply "work under the stress of necessity" (p. 80), including, we might add, the stress of the fantasy so central to healthcare: that sickness can be kept forever at bay and overcome by health.

\section{REFERENCES}

Abbott, P. and Wallace, C. (1990). The sociology of the caring professions. Basingstoke, UK: Falmer Press, Taylor and Francis, Inc.

Aram, E. and Baxter, R. (Eds.) (2009) Adaption and Innovation: Theory, Design and Role-Taking in Group Relations Conferences and their Applications. London: Karnac.

Baum, H. (1989). Organizational politics against organizational culture: A psychoanalytic perspective. Human Resource Management, 28(2), pp. 191-206. https:/ / doi.org/10.1002/hrm.3930280206

Bickman, L. (1996). A continuum of care: More is not always better. American Psychologist, 51(7), pp. 689-701. https://doi.org/10.1037/0003-066X.51.7.689

Bion, W. (1961). Experience in Groups. New York: Routledge. https:// doi.org/10.4324/9780203359075

Chang et al. (1998). Tennessee's Failed Managed Care Program for Mental Health and Substance Abuse Services. JAMA, 279(11), pp. 864-869. https://doi.org/10.1001/jama.279.11.864

Curlin, F.A., Dugdale, L.S., Lantos, J.D. and Chin, M.H. (2007). Do religious physicians disproportionately care for the underserved? Annals of Family Medicine, 5, pp. 353-360. https://doi.org/10.1370/afm.677

Diamond, M. (1988). Organizational Identity. Administration \& Society, 20(2), pp. 166-190. https://doi.org/10.1177/009539978802000203

Figley, C. (2005). Compassion Fatigue: An Expert Interview. Medscape, 17 October.

Figley, C. (Ed.) (1995). Compassion Fatigue: Coping with Secondary Traumatic Stress Disorder in Those Who Treat the Traumatized. New York: Routledge.

Freud, S. (1910). Leonardo da Vinci and a Memory of his Childhood. The Standard Edition of the Complete Psychological Works of Sigmund Freud, 11, pp. 57-138.

Freud, S. (1913). Totem and Taboo. In A. Brill, (Ed.), The Basic Writings of Sigmund Freud. New York: Random House.

Freud, S. (1918). From the history of an infantile neurosis. The Standard Edition of the Complete Psychological Works of Sigmund Freud, 17, pp. 1-122.

Freud, S. (1920). Beyond the Pleasure Principle. The Standard Edition of the Complete Psychological Works of Sigmund Frend, 18, pp. 1-64.

Freud, S. (1921). Group Psychology and the Analysis of the Ego. The Standard Edition of the Complete Psychological Works of Sigmund Frend, 18, pp. 61-144.

Freud, S. (1927). The Future of an Illusion. The Standard Edition of the Complete Psychological Works of Sigmund Freud, 19 , pp. $1-56$.

Freud, S. (1930). Civilization and Its Discontents. The Standard Edition of the Complete Psychological Works of Sigmund Freud, 21, pp. 64-148.

Futurescan (2008). Heathcare trends and implications 2008-2013. Chicago: Health Administration Press.

Haggerty, J.L., Roberge, D., Freeman, G.K. and Beaulieu, C. (2013). Experienced Continuity of Care When Patients See Multiple Clinicians: A Qualitative Metasummary. Annals of Family Medicine, 11(3), pp. $262-271$. https://doi.org/10.1370/afm.1499

Hirschhorn, L. (1989). Introduction to the Special Issue, "Organizational Psychodynamics." Human Resource Management, 28(2), pp. 157-160. https://doi.org/10.1002/hrm.3930280202 
Hirschhorn, L. and Young, D. (1991). Dealing with the anxiety of working: Social defenses as coping strategy. In M.F.R. Kets de Vries (Ed.), Organizations on the couch: Clinical perspectives on organizational behavior and change (pp. 215-240). San Francisco, CA: Jossey-Bass.

Jacques, E. (1953). On the dynamics of social structure. Human Relations, 6, pp. 3-24. https://doi.org/10.1177/001872675300600101

Kets de Vries, M. (Ed.) (1984). The irrational executive: Psychoanalytic studies in management. Madison, CT: International University Press.

Klein, M. (1937). Love, guilt, and reparation. In Love, Hate and Reparation. London: Hogarth Press.

Klein, M. (1946). Notes on some schizoid mechanisms. The International Journal of Psychoanalysis, 27, pp. 99-110.

Kripalani, S., LeFevre, F., Phillips, C.O., Williams, M.V., Basaviah, P. and Baker, D.W. (2007). Deficits in Communication and Information Transfer Between Hospital-Based and Primary Care Physicians: Implications for Patient Safety and Continuity of Care. JAMA, 297(8), pp. 831-841. https:// doi.org/10.1001/jama.297.8.831

Lacan, J. (1973). The Seminar of Jacques Lacan: The Four Fundamental Concepts of Psychoanalysis (Book XI). New York: Norton.

Levine, D. (2010). Object Relations, Work and the Self. New York: Routledge.

Menzies Lyth, I. (1960). A Case-study in the Functioning of Social Systems as a Defense Against Anxiety. Human Relations, 13, pp. 95-121. https:// doi.org/10.1177/001872676001300201

Menzies Lyth, I. (1991). Changing Organizations and Individuals. In M.F.R. Kets de Vries (Ed.), Organizations on the Couch. San Francisco: Josey-Bass.

Potter, P., Deshields, R. and Rodriguez, S. (2013). Developing a systematic program for compassion fatigue. Nursing Administration Quarterly, 37(4), pp. 326-332. https://doi.org/10.1097/NAQ.0b013e3182a2f9dd

Sadick, B. (2014). 'Physician burnout on the rise.' Chicago Tribune, 14 October.

Sievers, B. (Ed.) (2009). Psychoanalytic Studies of Organizations: Contributions from the International Society for the Psychoanalytic Study of Organizations. London: Karnac.

Slatten, L.A., Carson, K.D., Carson, P.P. (2011). Compassion fatigue and burnout: what managers should know. Health Care Management, 30(4), pp. 325-333. https:/ / doi.org/10.1097/HCM.0b013e31823511f7

Smart, D., English, A., James, J., Wilson, M., ..., Magera, C. (2014). Compassion fatigue and satisfaction: a crosssectional survey among US healthcare workers. Nursing \& Health Science, 16(1), pp. 3-10. https://doi.org/10.1111/nhs.12068

Tichy, N (1989). Editor's Note to the Special Issue, “Organizational Psychodynamics." Human Resource Management, 28(2), pp. 155-156.

Trist, E. and Sofer, C. (1959). Exploration in Group Relations. Leicester: Leicester University Press.

van Eeden, R. and Cillers, F. (2009). Social defense structures in organizations: how a lack of authorization keeps managers from moving to transformational leadership. International Journal of Organization Theory \& Behavior, 12(3), pp. 475-501. https://doi.org/10.1108/IJOTB-12-03-2009-B004

Wrzesniewski, A., Dutton, J.E. and Debebe, G. (2003). Interpersonal sensemaking and the meaning of work. Research in Organizational Behavior, 25, pp. 93-135. https://doi.org/10.1016/S0191-3085(03)25003-6

Yoder, E.A. (2010). Compassion fatigue in nurses. Applied Nursing Research, 23(4), pp. 191-197. https://doi.org/10.1016/j.apnr.2008.09.003 